ценными признаками, которые могут быть использованы в качестве исходного материала для селекции этой культуры в условиях предгорной зоны Северного Кавказа.

$$
* * *
$$

1. Доспехов Б. А. Методика полевого опыта (с основами статистической обработки результатов исследований) / Б.А. Доспехов. - Москва.: Колос, 1979. - 416 с.

2. Драгавцев, В.А. Эколого-генетическая организация количественных признаков растений и теория селекционных индексов / В.А. Драгав-цев // Экологическая генетика культурных растений: сб. докладов на Школе молодых ученых по экологической генетике. - Краснодар: ВНИИ риса. - 2012. - C. 31-50. 1.

3. Животков Л.А., Морозова 3.А., Секатуева Л.И. Методика выявления потенциальной продуктивности и адаптивности сортов и селекцион-ных форм озимой пшеницы по показателю урожайности // Селекция и семеноводство. - 1994. - № 2. - С. 3-6.

4. Патент на изобретение РФ 2710056 C1. 2019. Манукян. И.Р., Беку-зарова С.А., Басиева М.А. Мирошникова Е.С. Способ отбора высо-копродуктивных селекционных образцов озимых зерновых культур.

5. Манукян, И.Р., Басиева М.А. Использование селекционных индексов для оценки адаптивного потенциала коллекционных образцов ози-мой тритикале к условиям предгорной зоны Центрального Кавказа // Горное сельское хозяйство. - 2018. - № 2. - С. 33-37.

\title{
Мешурова Т.A. \\ К дополнению системы индикаторов и показателей деградированных и нарушенных земель для целей мониторинга
}

ФГБУ «Уральский государственный научно-исследовательский институт региональных экологических проблем» (Россия, Пермь)

doi: $10.18411 / s r-10-06-2021-11$

\section{Аннотация}

В статье отражен результат исследования системы индикаторов и показателей деградированных и нарушенных земель, представленной в ряде действующих российских нормативных правовых актов в области выявления, диагностики, мониторинга и восстановления деградированных и нарушенных земель, их рекультивации и поддержания в устойчивом состоянии. Рекомендованы и обоснованы изменения и дополнения системы индикаторов и показателей деградированных и нарушенных земель для целей их федерального мониторинга.

Ключевые слова: деградация земель, нормативные правовые акты, система индикаторов и показателей деградированных и нарушенных земель, опустынивание.

Хозяйственная деятельность человека зачастую приводит к деградации земель, почвы теряют свое плодородие или полностью разрушаются. Такое происходит, когда деяния человека являются нерациональными, экологически необоснованными. Деградация земель - ухудшение качества земель в результате негативного воздействия хозяйственной и (или) иной деятельности, природных и (или) антропогенных факторов. Нарушенными являются земли, деградация которых привела к невозможности их использования в соответствии с целевым назначением и разрешенным использованием [1].

Деградация земельных ресурсов вызвана не только действиями человека, она усугубляется природными процессами, в частности изменением климата. Наиболее значительными влияющими на продуктивность земель факторами являются обезлесение, чрезмерный выпас и расширение сельскохозяйственных, промышленных и городских районов. Косвенные движущие силы намного сложнее по своей природе и действуют в более крупных масштабах на большем расстоянии от района деградации. К ним относятся демографические тенденции, характер землевладения, хозяйственный 
уклад, изменение потребительского спроса, макроэкономическая политика быстрого роста. Прямые и косвенные движущие силы взаимодействуют, усиливая друг друга и в совокупности приводя к деградации земель [2].

Для последующей разработки мероприятий по предотвращению или минимизации негативного влияния деградированных и нарушенных земель на компоненты природы необходимо выявлять такие земли, прогнозировать динамику и оценивать влияние их на окружающую среду.

Индикаторы и показатели деградированных и нарушенных земель были разработаны еще в начале 90 -х годов. В конце прошлого столетия существовала направленность на борьбу с деградацией земель, на выявление и восстановление деградированных и загрязненных земель. В последние годы система мониторинга деградированных земель ослабла. Как отмечается в национальном докладе 2019 г. [2], в Российской Федерации отсутствует единая государственная система мониторинга деградации земель и опустынивания.

Для исследования системы индикаторов и показателей деградированных и нарушенных земель проводился анализ Методических рекомендаций по выявлению деградированных и загрязненных земель 1995 г. (далее Методические рекомендации) [3], Методики определения размеров ущерба от деградации почв и земель 1994 г. [4] и других действующих российских нормативных правовых актов в области выявления, диагностики, мониторинга и восстановления деградированных и нарушенных земель, их рекультивации и поддержания в устойчивом состоянии. Использовались научные публикации, доклады, материалы открытых источников по теме исследования.

Главными участниками системы государственного мониторинга земель являются Росреестр и Минсельхоз России, взаимодействуя в пределах своих полномочий с органами исполнительной власти субъектов Российской Федерации, органами местного самоуправления, а также территориальными органами Росимущества, Россельхознадзора, Росприроднадзора, органов, учреждений и организаций, подведомственных Минсельхозу России, Минприроды России. Ряд показателей мониторинга засух фиксируются Росгидрометом. В целом функции участников государственного мониторинга земель носят разрозненный, ведомственный характер [2].

Система индикаторов и показателей деградированных и нарушенных земель представлена в Методических рекомендациях 1995 г. [3] и в Методике определения размеров ущерба от деградации почв и земель 1994 г. [4]. На сегодняшний день эти документы требуют актуализации.

В Методических рекомендациях [3] более подробно представлена система индикаторов и показателей, по которым выявляют деградированные почвы и земли, чем в методике определения размеров ущерба от деградации почв и земель [4]. При определении степени деградации почв и земель в Методических рекомендациях предложено 34 показателя. Кроме того по каждому типу деградации имеется перечень диагностических и дополнительных показателей для выявления деградированных почв и земель. Для оценки эрозии используются статистические или динамические показатели, последние могут отражать как состояние почвенного покрова, так и ландшафтов. В перечне приложения 3 представлены 46 диагностических и 23 дополнительных показателя (для разных видов деградации). Нарушение земель и физическая (земледельческая) деградация оцениваются только по основным диагностическим показателям. Методические рекомендации не распространяются на земли, загрязненные радиоактивными веществами [3].

В Методике определения размеров ущерба от деградации почв и земель [4] представлена отдельная таблица «Определение степени деградации почв и земель», в которой выделены 23 индикаторных и 7 дополнительных показателей. Установление степени деградации почв и земель возможно по любому из предложенных 
индикаторных и (или) дополнительных показателей. При наличии двух и более существенных изменений индикаторных показателей оценка степени деградации почв и земель проводится по показателю, устанавливающему максимальную степень.

В результате анализа установлено, что при сборе информации о состоянии и использовании земель (кроме сельскохозяйственных) в субъектах Российской Федерации применяется термин «опустынивание» (как один из видов негативных процессов) в приказе Росреестра от 26.06.2015 № П/343 (приложение 12) [5], в приказе Минэкономразвития России от 26.12.2014 № 852 [6] (как качественный показатель состояния земель) и встречается в тексте Методических рекомендаций [3], но определения термина «опустынивание» в этих документах не приводится и соответственно не представлены индикаторы и показатели этого явления.

По информации, содержащейся в государственном докладе «О состоянии и об охране окружающей среды Российской Федерации в 2018 году» [7], основными негативными процессами, приводящими к деградации земель, почвенного и растительного покрова в федеральных округах, являются водная и ветровая эрозия, переувлажнение и заболачивание, подтопление, засоление, осолонцевание, опустынивание. Российская Федерация имеет сложные проблемы, связанные с процессами опустынивания земель, на юге страны. Глобальные изменения климата могут привести их к дальнейшему иссушению.

Автор [8] характеризует опустынивание как уменьшение или уничтожение биологического потенциала Земли, выражающееся в истощении наземных экосистем (уменьшении их биомассы, продуктивности, видового разнообразия), деградации земель, разрушении экологических ниш многих видов организмов, превращении продуктивных ландшафтов в пустынные в результате антропогенной деятельности и изменения климата.

Опустыниванию подвержены в первую очередь аридные или засушливые, земли тропиков с недостаточным и неустойчивым увлажнением. В Российской Федерации процесс опустынивания ярко выражен на так называемых «черных землях» в Калмыкии. Деградированные аридные земли в Астраханской, Волгоградской, Саратовской, Самарской областях и в Республике Татарстан занимают около 50 \% территории. Наблюдается деградация и опустынивание ландшафтов на территории аридной зоны Северо-Восточного Кавказа. Разрушающими факторами названы распашка земель, перевыпас скота, несоблюдение пастбище-оборота, водная эрозия, гидростроительство, населенные пункты и коммуникации $[2,8]$.

Снижение продуктивности оленьих пастбищ в тундровой зоне, усиливающиеся процессы эрозии и загрязнения земель в арктическом регионе приводят к опустыниванию. Многие из таких процессов получили в последние годы название «арктического опустынивания», для естественного восстановления которых требуются десятки и сотни лет [2].

Опустынивание земель в той или иной мере наблюдается в 27 субъектах Российской Федерации на территории площадью более 100 млн га. [2] По данным Росгидромета периодические засухи фиксировались в 2018 г. на половине территории нашей страны [9]. Проявление опустынивания на столь обширной площади требует разработки современных подходов к его диагностике.

Деградация лесов, как и опустынивание, - одно из проявлений глобальных изменений, происходящих на Земле. В лесном поясе все больше проявляется процесс обезлесения и снижения доли малонарушенных лесов - как своеобразной формы опустынивания бореальных ландшафтов [2]. В нашей стране ежегодно сгорают и вырубаются миллионы га лесных массивов.

Рекомендуется включить термин «опустынивание» с определением, сведения по индикаторам и показателям данного явления в понятийный аппарат российских 
нормативных правовых актов. Термин был введен Конвенцией Организации Объединенных Наций по борьбе с опустыниванием в странах, которые испытывают серьезную засуху и (или) опустынивание, особенно в Африке в 1994 г. [10].

Существенное значение при решении современных проблем устойчивого землепользования и для обоснования индикаторов состояния земель, особенно в регионах, подверженных опустыниванию, имеет задача достижения «нейтральной деградации земель» (далее НДЗ), вошедшая в число целей устойчивого развития на период после 2015 года $[2,11]$.

На Генеральной Ассамблее ООН в «Плане действий по устойчивому развитию до 2030 г.» для измерения результатов достижения целей бороться с опустыниванием, восстановить деградированные земли и почвы, стремиться достичь нейтральной деградации земель на глобальном уровне, принят индикатор «Отношение площади деградированных земельных ресурсов к общей площади земельных ресурсов». Мониторинг этого индикатора осуществляется на основе комбинированного использования трех субиндикаторов, а именно: почвенного покрова, продуктивности земель и запасов углерода над и под землей. К ним добавляются прочие индикаторы, которые рассматриваются в совокупности с данными на национальном и субнациональном уровнях [11].

Многие страны имеют правовую основу для достижения нейтрального баланса деградации земель. Ряд ученых являются сторонниками научной концепции НДЗ [12$14]$.

В результате анализа исследованных действующих российских нормативных правовых актов рекомендованы предложения по дополнению и корректировке системы индикаторов и показателей деградированных и нарушенных земель для целей их федерального мониторинга:

1. Предлагается дополнить Методические рекомендации по выявлению деградированных и загрязненных земель и Методику определения размеров ущерба от деградации почв и земель термином «опустынивание». «Опустынивание представляет собой деградацию земель в аридных, субаридных и засушливых субгумидных районах в результате действия различных факторов, включая изменение климата и деятельность человека» [10].

2. Целесообразно дополнить 2 раздел «Проведение работ по выявлению деградированных почв и земель» Методических рекомендаций [3] подпунктом, содержащим определение: «Нейтральная деградация земель-это такое состояние, когда количество здоровых и продуктивных земельных ресурсов, необходимое для поддержания жизненно важных экосистемных услуг и укрепления продовольственной безопасности, остается стабильным или увеличивается в определенных масштабах времени и пространства» [11].

3. Рекомендуется добавить в Методические рекомендации диагностические показатели явления опустынивания:

1) почвенная засуха (запасы продуктивной влаги в пахотном $\left(\mathrm{W}_{0-20}\right)$ и метровом $\left(\mathrm{W}_{0-100}\right)$ слоях почвы), мм или \%,

2) угнетение растений и снижение их биологической продуктивности (нарушаются основные физиологические процессы: фотосинтез, ростовые функции, дыхание, органогенез и др.).

Дополнительными показателями являются обезлесение, пастбищная дигрессия, сельскохозяйственная засуха. Обезлесение - исчезновение леса по естественным причинам и в результате хозяйственной деятельности человека [15]. Пастбищная дигрессия - ухудшение видового состава растительного покрова пастбищ под влиянием пастьбы [16]. Надежным показателем интенсивности засухи является снижение урожая по сравнению со средним многолетним значением. В агрометеорологии используются следующие показатели сельскохозяйственной засухи: очень сильная - снижение 
урожая более $50 \%$, сильная - снижение урожая от 20 до $50 \%$, слабая - снижение урожая на $20 \%$ [17].

4. Предлагается Методические рекомендации [3] дополнить приложением: «Индикаторные показатели нейтральной деградации земель».

Для оценки нейтральной деградации земель используется индикатор «Отношение площади деградированных земельных ресурсов к общей площади земельных ресурсов». Мониторинг этого индикатора осуществляется на основе комбинированного использования трех показателей:

- динамика наземного покрова (га),

- динамика продуктивности земель (т сухой массы на га в год),

- динамика запасов почвенного органического углерода для разных территорий с учетом географического разнообразия, типов природных и антропогенных изменений (т углерода на га).

Наземный покров - это видимая физическая оболочка поверхности Земли (Межправительственная комиссия по климатическим изменениям). Является базовым параметром поверхности Земли. Под продуктивностью земель понимается общая чистая первичная наземная продуктивность, определяемая как постоянная энергия растений минус их дыхание. Запас почвенного органического углерода - количество органического вещества в почве [11].

Показатели вычисляются на основе сравнимых и стандартизированных источников официальных национальных данных.

Если в течение какого-то времени по всем трем индикаторам (показателям) не наблюдалось ухудшений, то это говорит о том, что территория не деградирует. Если хотя бы по одному индикатору наблюдается какая-то негативная динамика, то это означает, что происходят деградационные процессы $[2,11]$.

Источником информации для оценки показателя динамики наземного покрова может служить набор данных Инициативы Европейского Космического Агентства по изменению климата (ESA-CCI-LC, 2016 г.). 37 классов наземного покрова (по классификации Всемирной Продовольственной Организации), объединены в 6 укрупненных категорий: сельскохозяйственные земли, леса, земли под травянистой растительностью, кустарниками, мохово-лишайниковой растительностью,

разреженной растительностью разных типов, болота, земли под застройкой, земли, лишенные растительного покрова, и прочие земли. Для определения показателя продуктивности земель используются данные Единого европейского исследовательского центра по динамике продуктивности земель. Глобальные данные по динамике запасов почвенного органического углерода в расчете на слой $30 \mathrm{~cm}$ агрегированы на исходных сведениях, содержащихся в базе данных SoilGrids Международного информационного центра по почвам, собранных для слоя 0-30 см по 6 обобщенным классам наземного покрова. SoilGrids представляет собой открытый тематический геоинформационный Web-сервис, обеспечивающий открытый доступ. Оценка и мониторинг основных показателей проводится с использованием специального тематического модуля геоинформационной системы Trends.Earth (Trends.Earth. Conservation International, 2018). Согласно методике оценки производится анализ изменения продуктивности земель, наземного покрова и запасов почвенного органического углерода по сравнению с «базовой линией». Исходные показатели должны подсчитываться для каждого индикатора как среднее значение за 10-15 лет [2, $11]$.

Дополнительными показателями являются соотношения между деградированными и улучшенными землями, уничтоженными / отчужденными и восстановленными землями, между продуктивными и непродуктивными, загрязненными и очищенными, и т. д. 
В результате проведенного анализа ряда нормативных актов в области выявления, диагностики, мониторинга и восстановления деградированных и нарушенных земель обоснованы рекомендуемые изменения и дополнения системы индикаторов и показателей деградированных и нарушенных земель для целей их федерального мониторинга. Предложено добавить термин «опустынивание» в Методические рекомендации [3] и в методику определения размеров ущерба от деградации почв и земель [4], термин «нейтральная деградация земель» в Методические рекомендации. Рекомендованы индикаторы и показатели «опустынивания» и НДЗ для внесения в нормативные правовые акты.

1. О проведении рекультивации и консервации земель: постановление Правительства РФ от 10.07.2018 № 800 .

2. Глобальный климат и почвенный покров России: опустынивание и деградация земель, институциональные, инфраструктурные, технологические меры адаптации (сельское и лесное хозяйство): национальный доклад / под ред. Р. С.-Х. Эдельгериева. - Москва: ООО «Издательство МБА», 2019. - Т. 2. - 476 с.

3. Методические рекомендации по выявлению деградированных и загрязненных земель: утв. Роскомземом от 28.12.1994, Минсельхозпродом России от 26.01.1995, Минприроды России от 15.01.1995.

4. О методике определения размеров ущерба от деградации почв и земель: утв. Минприроды России и Роскомземом от 29.07.1994: письмо Роскомзема от 29.07.1994 № 3-14-2/1139.

5. Об утверждении порядка организации деятельности и взаимодействия территориальных органов и структурных подразделений Федеральной службы государственной регистрации, кадастра и картографии при осуществлении государственного мониторинга земель: приказ Росреестра от 26.06.2015 № П/343.

6. Об утверждении порядка осуществления государственного мониторинга земель, за исключением земель сельскохозяйственного назначения: приказ Минэкономразвития России от 26.12.2014 № 852.

7. О состоянии и об охране окружающей среды Российской Федерации в 2018 году: государственный доклад. - Москва: Минприроды России; НПП «Кадастр», 2019. - 844 с.

8. Комарова, Н. Г. Геоэкология и природопользование: учеб. пособие для высш. пед. проф. образования / Н. Г. Комарова. - 4-е изд., перераб. и доп. - Москва: издательский центр «Академия», 2010. - $256 \mathrm{c.}$

9. Официальный сайт Росгидромета: раздел «Климатическая продукция»: Ежемесячный информационный бюллетень «Изменение климата», 2018. - № 71. - 32 с. - URL: http://meteorf.ru.

10. По борьбе с опустыниванием в тех странах, которые испытывают серьезную засуху и/или опустынивание, особенно в Африке: Конвенция Организации Объединенных Наций от 17.06.1994.

11. Постановка целей для нейтрального баланса деградации земельных ресурсов: Техническое руководство: Секретариат Конвенции ООН по борьбе с опустыниванием, 2016. - URL: https://www.unccd.int/sites/default/files/inlinefiles/LDN\%20TS\%20Technical\%20Guide_Draft_Russian. pdf.

12. Птичников, А. В. Применимость международных индикаторов оценки нейтрального баланса деградации земель к бореальным лесам России / А. В. Птичников., Д. В. Карелин, В. М. Котляков [и др.] // Доклады академии наук. - 2019. - Т. 489. - № 2. - С. 83-87.

13. Куст, Г. С. Нейтральный баланс деградации земель - современный подход к исследованию засушливых регионов на национальном уровне / Г. С. Куст, О. В. Андреева, В. А. Лобковский // Аридные экосистемы. - 2020. - Т 26. - № 2 (83). - С. 3-9.

14. Кудерина, Т. М. Атмосферное увлажнение как фактор нейтрального баланса деградации земель лесостепных ландшафтов / Т. М. Кудерина, С. Б. Суслова [и др.] // Аридные экосистемы. - 2020. T. 26. - № 2 (83) - C. 80-85.

15. Реймерс, Н. Ф. Охрана природы и окружающей человека среды: словарь-справочник / Н. Ф. Реймерс. - Москва: Просвещение, 1992. - 320 с.

16. Кормопроизводство. Термины и определения: ГОСТ 23153-78: утв. и введен в действие постановлением Государственного комитета стандартов Совета Министров СССР от 29.05.78 № 1453 с изменением № 1, утв. в дек. 1989 г. (ИУС 3-90).

17. Лосев, А. П. Агрометеорология / А. П. Лосев, Л. Л. Журина. - Москва: Колос, 2001. - 297 с. 